\title{
"Cabelo é como pensamento": entrelaçando combates antirracistas pelos fios de cabelo
}

\author{
Paulo Melgaço da Silva Junior \\ Ricardo Pinheiro de Almeida²
}

\begin{abstract}
RESUMO
Uma das características da contemporaneidade é uma explosão de identidades políticas centradas no feminismo e nas identidades gays, lésbicas e negras. Nessa pluralidade da vida social, interessa-nos refletir sobre os corpos negros como sujeitos que foram apagados pela modernidade e que sempre são apontados nos censos e nas pesquisas como em situação de inferioridade. A discussão sobre cabelo serve como um claro exemplo de temas que podem ser entrelaçados com o cotidiano escolar e que podem trazer grandes possibilidades de transformações no combate contra o racismo. Assim, este estudo aborda como uma professora de uma escola da periferia urbana de Duque de Caxias (RJ) entrelaça questões antirracistas pelos fios de seu cabelo - literal e metaforicamente - e em suas práticas. Observamos também os modos pelos quais duas alunas dessa professora são, positivamente, por ela impactadas. Os principais instrumentos para a geração de dados foram: as narrativas da professora e de duas alunas, a observação do cotidiano escolar e as anotações de conversas informais consideradas significantes. Tal processo evidenciou a importância de se trazer discussões visando ao combate ao racismo para o cotidiano escolar de modo que se apresentem aos/às estudantes outras possibilidades de sociabilidades que, por sua vez, ampliem o conhecimento de si próprios/próprias e do outro. Assim, também serão ampliadas a autoestima e o respeito ao próximo.
\end{abstract}

Palavras-chave: Cotidiano Escolar. Cabelos. Raça.

\section{"Hair is like thought":}

\section{intertwining antiracist combats by hair strands}

\begin{abstract}
One of the characteristics of contemporaneity is an explosion of political identities centered on feminism, gay, lesbian, and black identities. In this plurality of social life, we are interested in reflecting on black bodies as subjects that have been erased by modernity, and which are always pointed out in censuses and in researches as being

1 Pós-Doutorado e Doutorado em Educação pela UFRJ/RJ. Secretaria Municipal de Educação de Duque de Caxias/RJ. Professor Colaborador do Programa de Pós-Graduação em Artes Cênicas (PPGEAC) da UNIRIO/RJ. Rio de Janeiro, RJ. Orcid iD: http://orcid.org/00000002-4301-9305. E-mail: pmelgaco@uol.com.br

2 Mestrado em Língua Portuguesa pela UERJ/RJ. Docente no curso de Licenciatura em Letras da Universidade Castelo Branco (UCB)/RJ. Rio de Janeiro, RJ. Orcid iD: https://orcid.org/00000002-5347-4547. E-mail: ricardo.pinheiro.almeida@gmail.com
\end{abstract}


in an inferior situation. The discussion about hair serves as a clear example of themes that can be intertwined with daily school life, and that can bring great possibilities of transformation in the struggle against racism. Thus, this study approaches how a teacher from a school in the urban outskirts of Duque de Caxias (RJ) interweaves antiracist issues through the hair strands - literally and metaphorically - and in her practices. We also observe the ways in which two students of this teacher are positively impacted by it. The main instruments for the generation of data were the narratives of the teacher and two students, the observation of school daily life and the notes of informal conversations considered significant. This process evidenced the importance of bringing discussions aimed at combating racism into daily school life so that the students are presented with other possibilities of sociability that, in turn, increase the knowledge of themselves / themselves and the other. Consequently, self-esteem and respect for others will also be increased.

Keywords: School Environment. Hair. Race.

"El cabello es como el pensamiento":

\section{Entrelazando combates antirracistas por los hilos de cabello}

\section{RESUMEN}

Una de las características de la contemporaneidad es una explosión de identidades políticas centradas en el feminismo, en las identidades gays, lesbianas y negras. En esta pluralidad de la vida social, nos interesa reflexionar sobre los cuerpos negros como sujetos que fueron borrados por la modernidad y que siempre se mencionan en los censos y en las investigaciones como en situación de inferioridad. La discusión sobre el cabello sirve como un claro ejemplo de temas que pueden ser entrelazados con el cotidiano escolar y que pueden traer grandes posibilidades de transformaciones en el combate contra el racismo. Así, este estudio aborda cómo una profesora de una escuela de la periferia urbana de Duque de Caxias (RJ) entrelaza cuestiones antirracistas por los hilos de su cabello - literal y metafóricamente - y en sus prácticas. Observamos también los modos por los cuales dos alumnas de esta profesora son positivamente afectadas por ello. Los principales instrumentos para la generación de datos fueron: las narrativas de la profesora y de dos alumnas, la observación del cotidiano escolar y las anotaciones de conversaciones informales consideradas significantes. Tal proceso evidenció la importancia de traer discusiones para el combate al racismo para el cotidiano escolar de modo que se presenten a los / las estudiantes otras posibilidades de sociabilidades que a su vez amplíen el conocimiento de sí mismos / propias y del otro. Como así, también se amplía la autoestima y el respeto al prójimo.

Palabras clave: Cotidiano Escolar. Cabello. Raza.

\section{Introdução}

A esta altura do século XXI, uma pletora de estudos e de investigações acadêmicas e de outras esferas corroboram o seguinte fato inquestionável: 
a escola é o primeiro centro social de suma importância fora do núcleo familiar, onde as crianças poderão colocar em questionamento - ou mesmo confirmar - todas informações e visões de mundo ensinadas por seus familiares por meio de interações diárias, repetidas e, por fim, sedimentadas. Trata-se de um truísmo, claro está. Entretanto, parece-nos que, no que tange às questões envolvidas pelo tema educação, certos truísmos podem não ser tão truísmos quanto aparentam. Afinal de contas, a esta mesma altura do século XXI, também sabemos - graças às nossas experiências e/ou investigações - que é preciso repetir muito, em diversos lugares, as ideias que soam repisadas, isto é, os truísmos.

É necessário reconhecer que muitos saberes produzidos nas universidades sobre temas relacionados à educação, por exemplo, não são - nem ao menos remotamente - conhecidos, sequer incorporados às práticas em salas de aulas quando dos processos ensino-aprendizagem, os quais envolvem diversos atores sociais: docentes, estudantes e seus/suas familiares, coordenadores/coordenadoras, etc.

É igualmente importante compreender que nós ocupamos espaços de produção de conhecimento e, portanto, temos a responsabilidade ética de incitar reflexões, debates, críticas, revisões e ponderações de tal modo que aqueles/aquelas que nos leem e/ou ouvem sintam-se convidados/convidadas a saírem de onde estiverem e se deslocarem para um lugar incômodo, ou seja, o lugar da mudança cujos desdobramentos sejam transformadores de atos, de práticas e de fatos.

Posto isso, cumpre-nos esclarecer que neste texto interessa-nos refletir, específica e novamente, sobre o espaço da sala de aula. A proposta é pensar a escola a partir de suas relações cotidianas de raça e de gênero. Para tanto, argumentamos mais uma vez - e sempre - que esse local detém significativa importância na construção das identidades dos/as estudantes, incluídas aquelas de raça e de gênero.

No tangente à 'raça' e ao 'gênero' enquanto marcadores sociais, a escola é um dos primeiros locais onde estudantes negros/negras podem entrar em contato com uma visão nociva sobre a cor de sua pele. Tal visão 
pode estar interseccionada a uma visão de gênero igualmente nociva. Em tal espaço, meninos e meninas se veem expostos/expostas a brincadeiras, a reforços de senso comum, a xingamentos e a críticas, sendo excluídos/excluídas de diversas práticas sociais devido ao marcador corporal e às características a ele associadas.

Essas exclusões acontecem de duas maneiras: por um lado, o silêncio que invisibiliza a desigualdade racial, desencorajando alunos e alunas de se posicionarem como negros e negras. Por outro lado, nos espaços escolares, deparamo-nos com discursos que essencializam e naturalizam binarismos, cujos efeitos de sentido atingem indelevelmente a autoestima desses/dessas estudantes negros/negras. Os resultados dessa soma são o reforço e a naturalização de uma erva daninha estrutural e estruturante das relações sociais brasileiras (GOMES, 2017) chamada racismo.

Com efeito, a educação e a escola podem tanto contribuir para a perpetuação do racismo e para a manutenção dos discursos inferiorizantes sobre as pessoas negras em nossa sociedade, quanto podem ser agentes de transformação social e de lutas antirracistas. Nesse sentido, acreditamos que a escola possa oferecer uma grande contribuição ao problematizar as visões essencializadas de identidades raciais e de gênero e, com isso, fazer com que os/as estudantes reconheçam quão injustos são os sentimentos e as atitudes racistas, sexistas e quaisquer outras formas de preconceitos e de discriminações.

Sabe-se que, graças aos esforços do Movimento Negro educador (GOMES, 2017), há um grande contingente de estudantes negros/negras em salas de aula. Isso significa que vidas, corpos, experiências, vivências e culturas plurais coexistem nos espaços escolares. Os atores sociais abarcados em tais espaços não podem ignorar os fatos e nem tampouco negligenciálos. Truísmo ou não, a luta antirracista convoca todos e todas e, portanto, exige mudanças dos/nos pensamentos.

Considerando-se que, tal como pensamento, "cabelo vem de dentro [...] é como pensamento" e "pode ser trançado" (ANTUNES; BENJOR, 1989, não paginado), argumentamos pela urgência de se entrelaçarem os fios da 
luta antirracista às práticas e às posturas cotidianas em sala de aula. Nessa perspectiva, uma discussão em sala de aula sobre cabelos pode servir como um exemplo de tema pertinente e vivenciado no cotidiano escolar. Afinal de contas, quando se fala em cabelos, eles podem representar a marca de uma cultura? Podem empoderar e representar novas perspectivas e possibilidades de reconhecimento social?

Defendemos o argumento de que as escolas precisam buscar a inteligibilidade para todos os sujeitos, propor possibilidades de pensar em vidas que não são pensadas ou reconhecidas como tais. Como professores/professoras, temos a responsabilidade de prover normas de proteção para esses sujeitos. Tais questões não podem ser negligenciadas, devendo ser discutidas e problematizadas. Somos responsáveis pelo que escolhemos não ensinar às crianças. Segundo King e Schneider (1999), nossas escolhas dizem muito sobre o que valorizamos, sobre o que tememos e sobre como esperamos que esses valores sejam adotados por nossos/nossas alunos/alunas. Contudo, não se trata de introduzir um novo conhecimento ao currículo. A questão central é problematizar o conhecimento inscrito, desestabilizar os binários e as verdades construídas sobre gênero, sexualidades, raça e classe.

Assim, esta pesquisa se constitui numa tentativa de contribuir para conceber e investigar o repertório de significados e conceitos construídos a partir do senso comum e, com isso, buscar desestabilizar visões congeladas de raça e de gênero. O artigo está estruturado da seguinte maneira: no primeiro momento, apresentamos as reflexões iniciais. Em seguida, descrevemos o contexto em que se desenvolveu a investigação que serviu como fonte para geração de dados. Para encerrar, apresentamos as considerações finais.

\section{Algumas reflexões iniciais}

Raça e gênero são duas das questões responsáveis pelas hierarquizações sociais. A todo instante, em nossas diversas situações sociais, somos interpelados/interpeladas e classificados/classificadas a partir das 
expectativas que aquelas subjetividades criam para os outros sujeitos sociais. Ao longo da aventura civilizatória brasileira, mulheres negras e homens negros vêm sendo marcadas/marcados por meio de estigmas e narrativas essencialistas, fazendo com que muitos sujeitos tenham dificuldade de se aceitarem como pertencentes à raça negra.

Sodré (1999), Quijano (2001), Wilchins (2004) e Barnard (2004) defendem que a noção de raça é uma abstração ou uma fantasia móvel que em nada se relaciona ao determinismo biológico. Entretanto, Sommerville (2000) e Barnard (2004) entendem que as questões de raça, de gênero, de sexualidades e de classe social devem ser entrelaçadas ou interseccionadas, isto é, não podem ser desassociadas, visto que se deve observar um sujeito social como um todo, e não apenas por um ângulo de suas múltiplas, porosas, fluidas e cambiáveis subjetividades. Por esse caminho, entender como tais processos se interrelacionam torna-se indispensável para uma melhor reflexão e atuação nos diversos segmentos da sociedade que buscam consolidar a democracia a partir da redução das desigualdades de gênero e raça (CRENSHAW, 2004).

Faz-se necessário, neste momento, salientar a complexidade da questão racial no Brasil: no senso comum, encontramos ideias do determinismo biológico e do mito da democracia racial. O primeiro mostra as características biológicas inerentes à raça negra: aptidão inata para as atividades que exigem força e habilidades físicas. O segundo informa que em nosso país não existe racismo, que as oportunidades sociais são iguais para todos e todas. Contudo, nesta investigação, estamos pautados no princípio de que somos marcados e interpelados diariamente, conforme argumentamos no parágrafo que abre esta seção.

Dito isso, é oportuno recordar que as questões relacionadas à hierarquização e à subalternização de determinadas subjetividades, bem como as ações que justificam as violências contra o outro, estão pautadas no processo da chamada colonialidade. Segundo Mignolo (2007), a colonialidade envolve as relações de poder que emergiram no contexto do colonialismo europeu na Ásia, na África e na América. Contudo, seus efeitos 
não se limitam a este período histórico do domínio imperial, o qual legou várias consequências físico-psicológicas de subalternidades epistêmicas e racistas no Ocidente.

A despeito do encerramento do tempo histórico do regime colonialista, seus efeitos e suas reverberações ainda se fazem presentes nos modos como os conhecimentos são projetados e concebidos, por exemplo. Para Castro-Gómez (2005), a espoliação colonial foi autorizada por um conjunto de concepções de mundo que acabou por estabelecer as diferenças entre colonizadores/colonizadoras e colonizados/colonizadas.

Cabe destacar que os conceitos de colonialidade e de colonialismo, ainda que relacionados, não são equivalentes (WALSH, 2012). A colonialidade é mais duradora e envolve as relações de poder emergentes do/no contexto da colonização europeia, as quais têm mantido as associações entre dominação e subordinação, colonizador e colonizado, a despeito da emancipação das colônias. A colonialidade, por seu turno, é a parte constitutiva da modernidade, sendo, portanto, o seu lado sombrio, oculto e silenciado que determina a subalternização e a dependência (MIGNOLO, 2003).

Para justificar a proposta de dominação e de subalternização, a colonialidade foi um dos pilares da construção da modernidade, caracterizando a relação dicotômica entre o branco / europeu / racional / civilizado e o outro / não europeu / irracional / não civilizado. Desse modo, a a fabricação da ideia de raça acabou operando como dispositivo central no processo de hierarquização dos povos conquistados, justificando tanto as violências quanto as explorações.

Foi com base nessa perspectiva que Aníbal Quijano (2001) cunhou a expressão colonialidade do poder: a relação histórica responsável pela classificação e pela reclassificação das pessoas do planeta, que levou em conta a categoria raça como forma de controle social e de desenvolvimento do capitalismo mundial. Consequentemente, os/as colonizados/colonizadas veem seus modos de conhecimento e seus saberes reprimidos, inferiorizados e descaracterizados. 
Segundo Oliveira (2010, p. 40), a colonialidade do poder faz "alusão à invasão do imaginário do outro, ou seja, a ocidentalização. Mais especificamente, um discurso que se insere no mundo do colonizado, porém também se reproduz no lócus do colonizador"; além de lhe serem imputados novos conhecimentos. Nesse sentido, a visão heterossexual e branca/eurocêntrica seria parte da referida colonialidade, invisibilizando e subalternizando as identidades que não correspondem a tal padrão. Para Walsh (2009a), ao atravessar o campo do saber usado como dispositivo de dominação, esta perspectiva faz com que muitos discursos de intelectuais progressistas sejam desacreditados. Assim, conhecimentos historicamente produzidos pelos povos e comunidades colonizadas são negados, subestimados ou silenciados.

A partir desse eixo, outras possibilidades de colonialidade foram cunhadas. Um exemplo é a colonialidade do saber que está intimamente relacionada à geopolítica do conhecimento. Este, por sua vez, estabelece um paradigma de conhecimento universal e racional pautado nas produções eurocêntricas e na sua relação com o resto do mundo. Desse modo, outras formas de saber, outros conhecimentos e outras racionalidades advindas dos povos subalternizados são desqualificadas sobremaneira.

Outro exemplo é a colonialidade do ser que envolve um longo processo histórico de formação de identidades subalternizadas sob a hegemonia de uma herança colonial. Nesse caso, a não existência do outro - isto é, do/da colonizado/colonizada - é observada e discutida a partir de sua negação, de sua inferiorização e de sua desumanização sistemáticas: desconhece-se, assim, a alteridade e o outro é reduzido ao não-ser, condição que desqualifica e desmerece o seu valor.

Como já foi dito anteriormente, a colonialidade ocupa um lugar central nos processos de dominação e de subordinação. Nessa perspectiva, Mignolo (2003) argumenta que a diferença é de origem colonial. Em seu livro Histórias locais/projetos globais (MIGNOLO, 2003, p. 10), o autor defende que tal diferença está associada ao processo de colonização, sendo 
denominada "diferença colonial", ou seja, o espaço que se desdobra a partir da colonialidade do poder. Nas palavras do pensador:

[...] a diferença colonial é o espaço onde histórias locais que estão inventando e implementando os projetos globais encontram aquelas histórias locais que os recebem; é o espaço onde os projetos globais são forçados a adaptar-se, integrar-se ou onde são adotados, rejeitados ou ignorados (MIGNOLO, 2003, p. 10).

Para esse autor, o referido espaço pode ser físico ou imaginário. Nele atua a colonialidade do poder, que (re)configura historicamente uma geopolítica do conhecimento, na qual se destaca o privilégio de indivíduos localizados em determinados lugares geo-históricos do globo.

Interessante salientar que Lugones (2007) acrescentou a categoria gênero e buscou chamar a atenção para a importância deste nos processos econômicos e históricos nas formas de colonialidade. Ao tensionar a interseção entre as categorias raça, gênero e colonialidade, a autora afirma que existem os humanos - isto é, o homem branco, portador da inteligência e da razão, seguido da mulher branca - e os não humanos - quais sejam, negros/negras, nativos/nativas e outros/outras.

Em outro trabalho, Lugones (2014) caracteriza o gênero como uma ficção que sustenta a colonialidade do poder e a dominação racial. Só os civilizados são homens e mulheres. Os povos nativos das Américas e os/as africanos/africanas escravizados/escravizadas eram classificados como não humanos - como animais, incontrolavelmente sexuais e selvagens (LUGONES, 2014). Desse modo, "[...] pensar sobre a colonialidade do gênero permite-nos pensar em seres históricos compreendidos como oprimidos apenas de forma unilateral" (LUGONES, 2014, p. 939).

É relevante destacar que Lugones (2007) nos mostra que as mulheres negras e as indígenas não estão representadas nas categorias universais de mulher, de índio ou de negro. A crítica da autora é que essas categorias excluem as mulheres com especificidades relativas à raça e à classe, sendo necessário construir um feminismo decolonial para superar tal dominação sobre as mulheres não brancas. A autora propõe a interseção entre raça e 
gênero como uma forma de dar visibilidade às mulheres não brancas e de reconhecer suas lutas.

Outra grande contribuição de Lugones está no texto Subjetividad esclava, colonialidad de género, marginalidad y opresiones múltiples (2012). Nessa obra, a pesquisadora propõe a criação de um feminismo de resistência à dominação do modelo eurocêntrico, a ser defendido por mulheres que vivem e que sofrem diversas opressões, e que intersecione com as questões de raça, de classe e de gênero. A autora diz que a despatriarcalização só é possível se houver a descolonização do saber e do ser a partir de um feminismo decolonial (LUGONES, 2012).

Em retrospectiva, Lugones $(2007,2010)$ defende que a diferença colonial de gênero é uma marca da colonialidade de gênero e que essa deve ser trabalhada pelo feminismo decolonial, junto às questões das esferas da ecologia, da economia, do governo e do conhecimento, para citar algumas.

Seguindo tal caminho, neste texto, interessa-nos pensar as questões que relacionem mulheres negras, cabelo e escola. Para Walsh (2008), a perspectiva decolonial caminha no sentido de desafiar e de questionar as estruturas sociais, políticas e epistêmicas da colonialidade, denunciando os seus níveis de poder nos conhecimentos e, por sua vez, nas pedagogias. Walsh (2005) também destaca os possiveis caminhos para a efetivação de práticas inspiradas na pedagogia decolonial, situando-os em três âmbitos: o espaço da sala de aula, a formação docente e os materiais pedagógicos.

Conforme dito anteriormente, nós professores e professoras somos responsáveis pelo que escolhemos ensinar, valorizar ou silenciar. Nessa perspectiva, coadunamos com Pinar (2004): o currículo escolar incorpora o que escolhemos relembrar sobre o passado, o que acreditamos sobre 0 presente e o que esperamos do futuro. O currículo é um campo de lutas, de tensão, de disputa pelas relações de poder.

Com isso, afirmamos que entendemos como currículos de raça e gênero os espaços/tempos em que os sujeitos interagem, as ações escolares e culturais se desenvolvem e as renovadas tecnologias são empregadas. 
Nesse contexto, se ensina e se regula o corpo, produzindo subjetividades e arquitetando formas e possibilidades de viver em sociedade. O currículo é o espaço escolar onde se concentram e se desdobram lutas que ocorrem no seio da sociedade, em torno de diferentes significados sobre o social e o político (MOREIRA; SILVA JUNIOR, 2016).

Por esse caminho, torna-se imperativo levar a cultura afro-brasileira para as escolas e para os cotidianos. Em outras palavras, torna-se necessário interrogar, desconstruir os modos pelos quais as culturas e as identidades negras foram construídas pelo discurso eurocentrado, no qual o negro foi construído como o outro, como passível de destruição. Esse pensamento, apesar das lutas cotidianas, ainda está presente nos dias atuais.

Na Europa, o Mal é representado pelo negro. É preciso avançar lentamente, nós o sabemos, mas é difícil. O carrasco é o homem negro, Satã é negro, fala-se de trevas, quando se é sujo, se é negro tanto faz se isso se refira à sujeira física, à sujeira moral ou à sujeira moral-física. Ficaríamos surpresos se nos déssemos ao trabalho de reunir um grande número de expressões que fazem do negro o pecado. Na Europa, o preto, seja concreta, seja simbolicamente, representa o lado ruim da personalidade. Enquanto não compreendermos essa proposição, estaremos condenados a falar em vão do problema negro. O negro, o obscuro, a sombra, as trevas, a noite, os labirintos da terra, as profundezas abissais, enegrecer a reputação de alguém; e, do outro lado: o olhar claro da inocência, a pomba branca da paz, a luz feérica, paradisíaca. Uma magnífica criança loura quanta paz em sua expressão, quanta alegria e, principalmente quanta esperança! Nada comparável com uma magnifica criança negra, algo absolutamente insólito. Não vou voltar às histórias dos anjos negros. Na Europa, isto é, em todos os países civilizados e civilizadores, o negro simboliza o pecado. $O$ arquétipo dos valores inferiores é representado pelo negro (FANON, 2008, p. 160).

É relevante observar que a partir do domínio e da difusão do pensamento europeu, esta visão se consolidou em nosso país e, infelizmente, é defendida em diversos discursos e narrativas. Assim, todo este pensamento evidencia a necessidade de realizarmos estudos e possibilidades que interroguem e enfrentem o pensamento colonial e permitam pensar em outras possibilidades de ser.

Nesse sentido, graças às lutas dos movimentos sociais, em especial do Movimento Negro - que é também um educador, segundo Gomes (2017) - 
em 2003, foi promulgada a Lei 10.639 (BRASIL, 2003). Comos já se sabe, essa lei propõe novas diretrizes curriculares para o estudo da história e da cultura afro-brasileira e africana. Desse modo, espera-se que os professores/as professoras ressaltem em sala de aula a cultura afro-brasileira como constituinte e formadora da sociedade brasileira, de tal modo que as pessoas negras sejam consideradas como sujeitos históricos, valorizando-se, consequentemente, o pensamento e as ideias de importantes intelectuais negros/negras brasileiros/brasileiras, as culturas em suas diferentes manifestações (música, culinária, dança) e as religiões de matrizes africanas.

\section{Entrelaçando o antirracismo pelos fios de cabelo e em sala}

Uma das marcas do racismo diz respeito à subjetividade ferida de mulheres negras que percebem os cabelos crespos como defeito ou um problema. Nesse sentido, para diversas militantes e pesquisadoras das temáticas de gênero e de raça, assumir e valorizar o cabelo crespo compõem uma postura política individual e coletiva. Para bell hooks (2005, não paginado):

A realidade é que o cabelo alisado está vinculado historicamente e atualmente a um sistema de dominação racial que é incutida nas pessoas negras, e especialmente nas mulheres negras de que não somos aceitas como somos porque não somos belas.

A pensadora norte-americana ainda nos traz a seguinte provocação:

Em uma cultura de dominação e anti-intimidade, devemos lutar diariamente por permanecer em contato com nós mesmos e com os nossos corpos, uns com os outros. Especialmente as mulheres negras e os homens negros, já que são nossos corpos os que frequentemente são desmerecidos, menosprezados, humilhados e mutilados em uma ideologia que aliena. Celebrando os nossos corpos, participamos de uma luta libertadora que libera a mente e o coração (HOOKS, 2005, não paginado.)

Sobre este tema no Brasil, Gomes (2007) realizou uma pesquisa na qual destaca o papel importante desempenhado pela articulação entre cabelo e cor da pele na construção da identidade negra. A autora argumenta sobre a importância do cabelo no modo como as pessoas negras - inclusive aquelas que conseguem algum tipo de ascensão social - se veem e são 
vistas pelos outros. Assim, o cabelo tanto é uma forte marca identitária quanto, em determinadas situações, continua sendo visto como marca de inferioridade.

O cabelo do negro, visto como "ruim", é expressão do racismo e da desigualdade racial que recai sobre esse sujeito. Ver o cabelo do negro como "ruim" e do branco como "bom" expressa um conflito. Por isso, mudar o cabelo pode significar a tentativa do negro de sair do lugar da inferioridade ou a introjeção deste. Pode ainda representar um sentimento de autonomia, expresso nas formas ousadas e criativas de usar o cabelo. Estamos, portanto, em uma zona de tensão. É dela que emerge um padrão de beleza corporal real e um ideal. No Brasil, esse padrão ideal é branco, mas o real é negro e mestiço. O tratamento dado ao cabelo pode ser considerado uma das maneiras de expressar essa tensão. A consciência ou o encobrimento desse conflito, vivido na estética do corpo negro, marca a vida e a trajetória dos sujeitos. Por isso, para o negro, a intervenção no cabelo e no corpo é mais do que uma questão de vaidade ou de tratamento estético. É identitária (GOMES, 2007, p. 17).

Torna-se relevante apontar, neste momento, para a questão da identidade na situação da diáspora. Para Hall (2003), as identidades se tornam múltiplas.

Assim, a identidade é realmente algo formado, ao longo do tempo, através de processos inconscientes, e não algo inato, existente na consciência no momento do nascimento. Existe sempre algo "imaginário" ou fantasiado sobre sua unidade. Ela permanece sempre incompleta, está sempre "em processo", sempre "sendo formada". As partes "femininas" do eu masculino, por exemplo, que são negas, permanecem com ele e encontram expressão inconsciente em muitas formas não reconhecidas, na vida adulta. Assim, em vez de falar de identidade como uma coisa acabada, deveríamos falar de identificação, e vê-la como um processo em andamento (HALL, 2003, p. 38).

Posto isso, ressaltamos que partimos dos estudos decoloniais (LUGONES, 2012, 2014; WALSH, 2008) tanto para discutir a escola - e seus múltiplos e complexos atravessamentos culturais - quanto para observar as maneiras como duas jovens estudantes negras se constroem e revelam suas subjetividades no cotidiano escolar. O maior objetivo desta pesquisa foi atravessar limites, desconfiar e olhar de outros modos para o que está posto; colocar em situação embaraçosa o que há de estável naquele corpo de conhecimentos (LOURO, 2004). 
Em retrospectiva: apostamos na importância da realização de pesquisas na área educacional que se transformem em atividades relevantes e em oportunidades de aprendizagem, sempre numa perspectiva desestabilizadora, interrogativa e, certamente, antirracista.

Os dois principais instrumentos para a geração dos dados nesta investigação foram: (1) a observação dos marcadores e dos acessórios significados como racializados; (2) as conversas informais inspiradas no método das entrevistas episódicas. Esse último é apontado por Flick (2002) como surgido no contexto dos estudos relativos à representação social.

A entrevista episódica toma por base um guia de entrevista cuja finalidade é orientar o/a entrevistador/entrevistadora para os campos específicos a respeito dos quais se buscam respostas e/ou narrativas. Flick (2002) assevera que o guia de entrevista pode ser criado a partir de duas fontes distintas, a saber: (1) 0 conhecimento do/da pesquisador/pesquisadora relacionados às dimensões teóricas da área investigada, de outros estudos e de seus resultados; (2) a experiência do/da pesquisador/pesquisadora na área estudada.

Desse modo, é importante desenvolver uma compreensão preliminar da área em estudo, de forma que as partes relevantes possam ser abrangidas, que as perguntas possam ser bem formuladas e que o guia possa permanecer suficientemente aberto para acomodar novos aspectos que venham a emergir com os/as entrevistados/entrevistadas (FLICK, 2002). Assim, a produção de dados foi facilitada pelo fato de que um dos pesquisadores envolvidos na geração dos dados atua na escola/espaço observado. Isso também auxiliou na participação das jovens envolvidas, com livre consentimento, na produção dos dados.

Os marcadores e os acessórios foram confirmados nas conversas e seguiram uma lógica de investimento e de planejamento. Nessas ações, os corpos foram tomados como suportes de currículos de raça reproduzidos, criados e ensinados nas escolas. Eles são os lócus de produção e de expressão da cultura em que os cabelos, a raça e o gênero passaram a ser significados. Assim, os currículos prescritos e/ou praticados pelos inúmeros 
sujeitos da escola ganham importância por serem um dos dispositivos pelos quais a escola executa a formação nos corpos dos sujeitos.

A Escola do Cantão3, onde os dados do presente texto foram gerados, está localizada em um bairro da periferia de Duque de Caxias (RJ), cidade da Baixada Fluminense, e oferece desde a Educação Infantil ao segundo segmento do Ensino Fundamental. A escola possui aproximadamente 700 alunos/alunas provenientes de classe trabalhadora e economicamente desfavorecida.

Cumpre destacar que além de ser pesquisador, um dos autores deste artigo leciona na Escola do Cantão. Quando lá chegou em 2016, uma das questões que mais chamaram sua atenção foi o fato de a maioria das alunas negras do Fundamental 2 - isto é, do $6^{\circ}$ ao $9^{\circ}$ ano - usarem cabelos ao natural, enfeitados com flores ou laços e com tranças. Algumas usavam até turbantes.

A segurança de tais alunas e suas elevadas autoestimas como mulheres negras aguçaram sua curiosidade, visto que o referido pesquisador não presenciara essas atitudes em outra unidade escolar, também integrante da rede municipal de Duque de Caxias (RJ). Nesta, as alunas negras demonstraram grande dificuldade em aceitar como belos seus cabelos e seus próprios traços físicos, atitudes diametralmente opostas às daquelas tomadas pelas alunas da Escola do Cantão.

Em sua entrevista, a professora negra Juliana ${ }^{4}$ revelou que trabalhava na Escola do Cantão havia 22 anos. Ela também revelou que era muito nova e recém-formada quando iniciou seu ofício de docente naquela escola. Juliana considera que sua pouca idade e sua inexperiência foram os motivos pelos quais ela não pensava em determinadas questões, tais como as que dizem respeito à raça e/ou ao gênero.

Conforme nos mostra Costa de Paula (2010), a mulher negra pode se mostrar insegura em relação à própria imagem por causa do cabelo, o que

\footnotetext{
${ }_{3}^{3}$ Nome fictício, escolhido pelo fato de a escola estar localizada em uma região afastada do $2^{\circ}$ distrito de Duque de Caxias chamada pelos/pelas moradores/moradoras de 'Cantão'.

4 Nome fictício.
} 
nos pareceu ser o caso da professora em tela: em entrevista, Juliana nos confidenciou que outrora alisara os cabelos de modo a se encaixar, sem sucesso, no modelo hegemônico de beleza. Para tanto, além de alisar os cabelos, essa professora negra se engajou numa variedade de dietas para emagrecer e, assim, reduzir o tamanho de suas coxas e quadril para se adequar ao modelo hegemônico. Entretanto, lucidamente Juliana também confidenciou que não levara em consideração o fato de que as mulheres negras geralmente têm quadris, coxas e corpos naturalmente mais acentuados do que os das mulheres brancas.

Curiosamente, ainda que buscasse por meios e caminhos - tortuosos um pertencimento ou encaixamento aos padrões de beleza hegemônicos, a professora negra Juliana frequentava aulas de dança afro e tinha contato com pessoas que discutiam questões das culturas de matrizes afro-brasileiras. Mesmo assim, até então, nossa entrevistada não atinara para o entrelaçamento de suas práticas docentes com suas outras sociabilidades, como por exemplo a dança afro.

De acordo com a professora Juliana, há aproximadamente onze anos, aconteceu a grande virada em sua vida. Reproduzimos a seguir suas palavras:

\footnotetext{
"Aconteceu uma mistura de situações que foram desencadeando aos poucos. Primeiro, foi um problema pessoal que enfrentava. Com isso, eu resolvi me assumir como mulher negra: mudei o cabelo, parei de alisar, mudei o modo de vestir."
}

Essas mudanças certamente chamaram atenção de todos e todas na Escola Cantão: professores/professoras, alunos/alunas, funcionários/funcionárias dos setores técnico e administrativo perceberam que havia algo muito diferente. Juliana nos contou que um dia, numa sala de aula, ocorreu isto:

"Um aluno criou coragem, virou para mim e perguntou se eu ia ficar assim, daquele jeito, feia e jogada como as meninas da escola... que eu tinha que voltar a arrumar os cabelos... imagina o choque... aí, comecei a entender o pensamento e os olhares de alguns colegas." 
Com base nesse excerto da entrevista da professora negra Juliana, podemos reafirmar que, desde o processo de colonização, as pessoas negras têm sido construídas como naturalmente inferiores, e que as diferenças foram sempre marcadas de modo relacional, isto é, em relação às pessoas brancas (WALSH, 2012).

Uma vez que a professora Juliana estava em franca mudança de mentalidade ou pensamento - que, assim como os cabelos, vem de dentro (ANTUNES; BENJOR, 1989) -, naquele mesmo dia em que percebeu os estranhamentos, ela buscou mostrar e discutir com a turma que, enquanto ser branco/branca significa ser bonito/bonita, ser negro/negra corresponde a ser feio/feia.

Ela também destacou que o cheiro do/da branco/branca é tomado como bom, ao passo que ao/à negro/negra é historicamente legado o lugar do mau cheiro, da sujeira e da ausência de higiene. Juliana lançou mão de várias outras comparações social e historicamente construídas e disseminadas. É provável que muitas pessoas negras as conheçam - por experiência própria ou por relatos de outrem -, incluindo todos aqueles atributos relativos aos cabelos, especialmente aos das mulheres negras.

Destacamos que, embora a professora Juliana estivesse fazendo alusão principalmente aos cabelos, o cerne de suas comparações pode ser estendido a todas as condições que reduzem os/as negros/negras ao nível inferior em múltiplos aspectos de suas subjetividades. Em última instância, ela estava experimentando novas formas de identificação, e não mais aquelas relacionadas aos processos de determinismo biológico ou social (SOMMERVILLE, 2000; BARNARD, 2004).

Esses episódios contribuíram para que a professora iniciasse seu trabalho, agora comprometido e agenciador de mudanças de mentalidades. Em outras palavras: a professora negra Juliana estava ali, no nível micro e situado, entrelaçando fios dos combates antirracistas com suas práticas em sala de aula. Em vez de ignorar os comentários e olhares reprovadores - e mesmo constrangedores -, a professora decidiu dialogar, debater, fazer refletir. Juliana ainda nos disse o seguinte: 
Foi então que resolvi desenvolver um trabalho na escola. Comecei a sentir o quanto que as pessoas estavam comprometidas com um modelo de beleza e os negros não se encaixavam neste modelo. Então, senti que tinha que começar a trabalhar, fazer alguma coisa, principalmente com as alunas negras como eu, e com os meninos também... Nunca fiz projetos ou parei a escola para festas especiais. Eu sempre tive muitas turmas aqui na escola, então, eu conhecia quase todos alunos da escola. Então, eu trabalhava com pequenos grupos, conversava com pequenos grupos de alunas, discutia beleza, possibilidades de usar cabelos naturais ou cacheados, tipos de roupas, enfim, como a mulher negra pode ser bonita sem copiar as brancas. Sentia que as meninas foram se aproximando, acreditando e mudando comigo. Ao longo destes anos, coloquei trança, usei turbantes, cortei curtinho, usei flores, laços, entre outros. Sempre conversando muito com os alunos e alunas. Sempre trago fotos de negros, procuro montar danças negras nas festas das escolas e integrar a minha disciplina que é a geografia... Não vejo minha atividade aqui na escola como um trabalho extraclasse... mas como curricular. Me gratifica muito saber que meu posicionamento, que era pessoal, acabou influenciando muitas meninas... Verdade, em uma escola com a maioria negra, são poucas as que alisam cabelos. Veja principalmente no $8^{\circ}$ e $9^{\circ}$ anos, cada uma busca valorizar sua beleza... tem menina de trança, com flor, com fita... eu mesma trago muitos enfeites, arcos, laços e dou para elas... quero vê-las poderosas... com autoestima elevada... é interessante que os meninos aprenderam a respeitar e achar as meninas negras bonitas e atraentes...

Cumpre salientar que as ações da professora podem nos remeter à proposta de efetivação de práticas inspiradas na perspectiva decolonial (WALSH, 2005, 2008), isto é, Juliana buscou espaços na escola que permitissem tensionar os discursos hegemônicos sobre raça e sobre gênero.

Mesmo não trabalhando com o currículo formal, as (re)ações pedagógicas de Juliana nos levam a considerar como essa professora privilegiou a prática pedagógica cotidiana e, procedendo dessa maneira, conseguiu quebrar o silêncio que tanto apaga, negligencia e invisibiliza as questões raciais na escola, quanto desumaniza as mulheres negras. Nesse aspecto, ao propor a interseção entre raça e gênero, provavelmente Juliana estava em busca da visibilidade e do reconhecimento (LUGONES, 2007) das vidas, dos corpos e das lutas de suas alunas negras.

Claro está que toda ação traz reação. Entretanto, muito mais interessante do que repetir o truísmo, é comprovar com relatos de pessoas que se beneficiaram da postura e das práticas antirracistas entrelaçadas pelos fios de cabelo e de pensamento da professora Juliana. 
O comentário a seguir, feito pela aluna Letícia $^{5}$ do $9^{\circ}$ ano daquela unidade escolar, pode nos dar a dimensão do impacto do trabalho desenvolvido pela professora em tela:

Olha, a professora Juliana é uma das melhores professoras desta escola. Estudo com ela deste $\circ 6^{\circ}$ ano. No ano passado, coloquei tranças, foi depois que ela colocou... nós conversamos, ela colocou primeiro, as delas eram compridas, muito bonitas... já viu como ela amarra? Então eu animei, várias meninas colocaram... a Juliana sempre conversou com a gente sobre a beleza da mulher negra. Tem um grupo aqui que diz que somos filhas dela... sempre que ela pode, ela traz uns presentinhos para as meninas, enfeites de cabelo, brincos para realçar a beleza... ela diz muito que temos que nos amar, nos achar bonitas... ela fala que a mulher negra tem que acreditar no seu potencial e ter autoestima...

Se por um lado a pesquisa desenvolvida por Costa de Paula (2010) nos mostra que as meninas negras querem ser bonitas, indo além da discussão binária sobre alisar ou não alisar os cabelos, por outro lado, o depoimento da aluna Letícia somado às observações do cotidiano nos revelam que as meninas negras, apoiadas por uma ampla discussão de gênero e de raça, se sentem com a autoestima elevada e, consequentemente, assumem seus cabelos de acordo com as possibilidades de suas raças, sem traços de sentimentos de inferioridade.

Entrevistamos outra aluna do $9^{\circ}$ ano, Jéssicab ${ }^{6}$, e buscamos saber em quais momentos a professora Juliana promovia discussões acerca dos temas raça e gênero. Nós também procuramos saber como era a relação dessa professora com o conteúdo de geografia, disciplina sob sua regência. A aluna prontamente respondeu o seguinte: "Ela trabalha normal... dá o livro, passa exercícios, dá trabalhos...".

A partir dessa resposta, fizemos mais duas perguntas: "Então qual é a diferença? Em que momentos a professora Juliana conversa com vocês?" A aluna Letícia respondeu o que segue:

Ela conversa muito com a gente nos horários de folga, no recreio... na sala de aula também... ela sempre junta um assunto do livro com um assunto da gente... quando tem um assunto no livro... se aparece

\footnotetext{
${ }^{5}$ Nome fictício.

6 Nome fictício.
} 
uma família branca... ela traz uma família negra... se aparece um homem, ela traz uma mulher... ela sempre traz coisas de fora para misturar... nas aulas, tem sempre uma conversa... tem professor que reclama, porque quase sempre na aula dela a gente fica em roda... e eles falam que atrapalha a sala... sempre antes dela chegar... a gente já arruma a sala e antes dela sair, volta tudo igual... para ninguém reclamar...

Posto isso, acreditamos que a professora Juliana está desenvolvendo o feminismo de resistência à dominação, conforme proposto por Lugones (2012). Ao buscar que os/as alunos/alunas tensionem as questões de gênero e de raça, e ao trazer para a escola as discussões sobre cabelos, certamente, a professora está, a seu modo, convocando algumas meninas negras - que, em geral, vivem algumas opressões de raça, de classe social e de gênero - para a apropriação de suas lutas e o enfrentamento de suas questões.

\begin{abstract}
Por mais que a escravidão e a diáspora negra tenham obtido sucesso na despersonalização do negro, por mais que a mistura racial tenha mesclado corpos, costumes e tradições e por mais que o contato com o branco tenha disseminado um processo de discriminação intra-racial entre os negros e introduzido uma hierarquização racial que elege o tipo de cabelo e a cor da pele como símbolos de beleza e feiúra, todo esse processo não conseguiu apagar as marcas simbólicas e reais que nos remetem à ascendência africana. O corpo, a manipulação do cabelo são depósitos da memória (GOMES, 2008, p. 321).
\end{abstract}

Em outros termos, poder-se-ia dizer que a professora Juliana tem buscado entrelaçar fios de combates antirracistas com suas práticas pedagógicas de modo paulatino, consciente e engajado. Mesmo sabendo que a luta é longa e árdua, em vez de negligenciar ou negar a existência do racismo, a professora em tela optou - desde o episódio-chave que a levou à mudança de mentalidade - por abraçar a causa a sua maneira e dentro de suas possibilidades de agenciamento.

Por fim, "Quem disse que cabelo não sente"? (ANTUNES; BENJOR, 1989, não paginado.) 


\section{Considerações finais}

A questão que esteve implícita ao longo do texto foi o entrelaçamento de combate antirracista pelos fios de cabelo - literal e metaforicamente realizado por Juliana, uma professora negra de uma escola pública do município de Duque de Caxias (RJ). Interessou-nos também obter relatos de duas alunas negras da mesma escola com o intuito de perceber o impacto que a postura e as práticas docentes antirracistas tiveram sobre essas alunas.

Assim, a proposta do presente estudo foi mostrar como as marcas culturais influenciam as formas de agir e de pensar, podendo inferiorizar algumas identidades, reforçando estigmas, preconceitos e naturalizando o que jamais fora 'natural'.

Acreditamos que um trabalho construído de maneira sistemática e constante, que promova possibilidades de valorações positivas de gênero e de raça, possa (res)significar a construção de caminhos de resistência à dominação colonial que marcam o outro.

Tais discussões confirmaram a relevância de se entrelaçarem, no cotidiano escolar e nas salas de aula, fios relativos ao gênero e à raça, independentemente de disciplina ou matéria, de se por um minuto ou por um ano letivo completo. Seja no nível micro, seja no macro, o que importa é dar prosseguimento às atividades, práticas e posturas que desafiem o jádado e, consequentemente, desnaturalizem - ou minimamente, perturbem o que é considerado natural ou normal.

A atuação da professora em tela pode ser aproximada daquilo que Gomes (2008) em seu estudo no interior de salões étnicos destaca ao afirmar que, mesmo sem a clareza da força da sua atuação, esses salões muitas vezes desempenham o papel de "restaurar importantes elos entre o negro e a sua autoestima" (GOMES, 2008, p. 32).

Ressaltamos a relevância de ocupar espaços na escola, de reconhecer o currículo - entendido em seu sentido mais amplo, como campo de lutas em torno de significações - e com isso buscar lacunas e fissuras que permitam questionar o que está posto. Essas ações podem contribuir para melhor compreender problemas que envolvem exclusão ou 
silenciamentos de alunos e alunas em salas de aula e, ao mesmo tempo, permitindo que valorizem seus modos de viver, de saber e suas culturas.

Nesse sentido, o tema cabelo contribui para o entrelaçamento e o tensionamento de diversas questões sociais e, sobretudo, para o empoderamento de algumas meninas negras nas escolas. Como resultado de tal empoderamento, podemos destacar uma tentativa de enaltecer a beleza negra e, consequentemente, a elevação da autoestima daquelas alunas.

O trabalho realizado pela professora Juliana colocou em xeque mesmo que brevemente - certas visões essencializadas e os congelamentos identitários, trazendo o/a diferente, isto é, o/a colonizado/colonizada, para a sala de aula, e promovendo o diálogo entre as diferenças. Juliana sabe que cabelo é como pensamento: vem de dentro e pode ser cruzado, trançado e bonito.

\section{Referências}

ANTUNES, A; BENJOR, J. Cabelo. Rio de Janeiro: Warner Music, 1989.

Disponível em: <http://www.arnaldoantunes.com.br/new/sec_discografia_ sel.php?id=124>. Acesso em 1 fev. 2019.

BARNARD, I. Queer race. New York: Lang, 2004.

BRASIL. Lei 10.639, de 9 de janeiro de 2003. Diário Oficial da União, 10 de janeiro de 2003. Altera a Lei no 9.394, de 20 dez. 1996, que estabelece as diretrizes e bases da educação nacional, para incluir no currículo oficial da Rede de Ensino a obrigatoriedade da temática "História e Cultura AfroBrasileira".

CASTRO-GÓMEZ, S. Ciências sociais, violência epistêmica e o problema da "invenção do outro". In: LANDER, E. (Org.). A colonilidade do saber: eurocentrismo e ciências sociais. Perspectivas latino-americanas. Buenos Aires: CLASCO, 2005. p. 80-77.

COSTA DE PAULA, R. "Não quero ser branca não. Só quero um cabelo bom, cabelo bonito" - Performances de corpos/cabelos de adolescentes negras em práticas informais. 2010. 298f. Tese (Doutorado em Linguística Aplicada) Instituto de Estudos da Linguagem. Universidade Estadual de Campinas, Campinas/SP, 2010. 
CRENSHAW, K. W. A intersecionalidade na discriminação de raça e gênero. Cruzamento: raça e gênero. Brasília: Unifem, 2004. p. 7-16.

FANON, F. Pele negra, máscaras brancas. Trad. Renato Silveira, Salvador: EDUFBA, 2008.

FLICK, U. Entrevista Episódica. In: BAUER, M. W.; GASKELL, G. (Orgs.). Pesquisa Qualitativa com Texto, Imagem e Som - Um manual prático. 2. ed. Trad. Pedrinho A. Guareschi. Petrópolis/RJ: Vozes, 2002. p. 114-136.

GOMES, N. L. O movimento negro educador: saberes construídos nas lutas por emancipação. Petrópolis, RJ: Vozes, 2017.

GOMES, N. L. Sem perder a raiz - Corpo e cabelo como símbolos da identidade negra. Belo Horizonte: Autêntica, 2007.

HALL, S. A identidade cultural na pós-modernidade. 7. ed. Rio de Janeiro: DP\&A, 2003.

HOOKS, B. Alisando o nosso cabelo. Revista Gazeta de Cuba - Union de escritores y artista de Cuba, Trad. Lia Maria dos Santos, p. 1-8, jan-fev. 2005. Disponível em: <http://www.geledes.org.br/alisando-o-nosso-cabelo-porbellhooks/\#axzz3ZBBwtlph>. Acesso em: 04 fev. 2019.

KING, J. R.; SCHNEIDER, J. J. Locating a place for gay and lesbian themes in elementary reading, writing and talking. In: LETTS, W. J.; SEARS, J. (Edits.).

Queering elementary education: advancing the dialogue about sexualities and schooling. New York: Rowman \& Littlefield Publishers, 1999. p. 3-14.

LOURO, G. L. Os estudos feministas, os estudos gays e lésbicos e a teoria queer como políticas de conhecimento. In: LOPES, D. et al (Orgs.). Imagem e diversidade sexual: estudos da homocultura. São Paulo: Nojosa, 2004. p. 2328.

LUGONES, M. Heterosexism and the colonial/modern gender system. Hypatia - A Journal of Feminist Philosophy, v. 22, n. 1, Indiana/USA, p. 186-219, Feb. 2007. Disponível em: <http://onlinelibrary.wiley. com/wol1/doi/10.1111/j.15272001.2007.tb01 156.x/full>. Acesso em: 8 dez. 2018.

LUGONES, M. Rumo a um feminismo descolonial. Estudos Feministas,

Florianópolis, v. 22, n. 3, p. 935-952, set/dez 2014. Disponível em: <https://periodicos.ufsc.br/index.php/ref/article/view/36 755/28577>. Acesso em: 15 fev. 2017.

LUGONES, M. Subjetividad esclava, colonialidad de género, marginalidad y opresiones múltiples. Pensando los feminismos en Bolivia. Serie Foros 2. La Paz: Conexión Fondo de Emancipación, 2012. p.129-140. Disponível em: 
<http://www.conexion.org.bo/uploads/Pensando_los_Feminismos_en_Boli via.pdf >. Acesso em: 10 jan. 2019.

LUGONES, M. Toward a decolonial feminism. Hypatia - A Journal of Feminist Philosophy, v. 25, n. 4, Indiana /USA, p. 742-759, 2010. Disponível em: <http://onlinelibrary.wiley.com /wol1/doi/10.1111/j.1527-2001.2010.01137.x/ full>. Acesso em: 10 jan. 2019.

MIGNOLO, W. Histórias locais/ projetos globais: Colonialidade, saberes subalternos e pensamento liminar. Trad. Solange Ribeiro de Oliveira. Belo Horizonte: UFMG, 2003.

MIGNOLO, W. La idea de América Latina: la herida colonial y la opción decolonial. Barcelona: Gedisa, 2007.

MOREIRA, A. F. B; SILVA JUNIOR, P. M. Currículo Transgressão e Diálogos: Quando outras possibilidades se tornam necessárias. Revista Tempos e Espaços em Educação, v. 9, n. 18, p. 45-54, jan./abr. 2016.

OLIVEIRA, L. F. Histórias da África e dos africanos na escola: as perspectivas para a formação dos professores de história quando a diferença se torna obrigatoriedade curricular. 2010.281 f. Tese (Doutorado em Educação) Pontifícia Universidade Católica do Rio de Janeiro - Rio de Janeiro, 2010.

PINAR, W.F. What is curriculum theory? Mahwah, NJ: Erlbaum, 2004.

QUIJANO, A. Colonialidad del Poder, Globalización y Democracia.

Tendencias básicas de nuestra época: globalización y democracia, v. 1 de Cuadernos (Instituto de Altos Estudios Diplomaticos Pedro Gual) Caracas: Ministerio de Relaciones Exteriores / Instituto de Altos Estudios Diplomáticos Pedro Gual, 2001, p. 25-61.

SODRÉ, M. Claros e escuros. Petrópolis, RJ: Vozes, 1999.

SOMERVILLE, S. B. Queering the color line: race and the inventation of homosexuality in American culture. Durham: Duke University Press, 2000.

WALSH, C. Interculturalidade crítica e pedagogia decolonial: in-surgir, reexistir e re-viver. In: CANDAU, V. (Org.). Educação intercultural na América Latina: entre concepções, tensões e propostas. Rio de Janeiro: 7 Letras, 2009b. p. 12-42.

WALSH, C. Interculturalidad, plurinacionalidad y decolonialidad: Ias insurgencias político-epistémicas de refundar el Estado. Tabula Rasa, n. 9, Bogotá, p. 131-152, jul./dic., 2008. 
WALSH, C. Interculturalidad y (de)colonialidad: perspectivas críticas y políticas. Visão Global, v. 15, n. 1-2, Joaçaba, p. 61-74 jan./dez., 2012.

Disponível em: <https://editora.unoesc.edu. br/index.php/visaoglobal/article /view/3412>. Acesso em: 1 de março de 2013

WALSH, C. Interculturalidad y (de)colonialidad: perspectivas criticas y políticas. CONGRESSO ARIC, 12., 2009, Florianópolis. Anais... Florianópolis: ARIC, 2009a.

WALSH, C. La Interculturalidad en la Educación. Lima-Perú: Unicef; Ministerio de Educación, 2005. Disponível em: <https://www.unicef.org/peru/_files/Pu blicaciones/Educacionbasica/peru_educaci on_.pdf >. Acesso em: $15 \mathrm{fev}$. 2019.

WILCHINS, R. Queer theory, gender theory. Los Angeles: Alysson Books, 2004.

Recebido em: 15 de fevereiro de 2020 Aprovado em: 09 de junho de 2020

Publicado em: 28 de agosto de 2020 